\title{
SABA over-reliance; time for a change
}

\section{Opinion}

All Asthma guidelines have traditionally recommended that the first step for Asthma management is to treat the symptoms with a Short Acting Beta Agonist (SABA). This also mirrors most asthmatics first step in their asthma journey. The patient presents to their clinician with shortness of breath, cough or wheeze and is given a blue inhaler which makes them feel better, and that relationship is forged for life. However, as we contemplate the fact that asthma outcomes are not as we would like, ${ }^{1}$ we recognize that one of the fundamental reasons for this is the patients' reliance on their SABA. A recent paper on the Paradoxes of Asthma Care, highlighted the issue of SABA overreliance and ICS underuse as the fundamental issue and breaks it down to five areas. SABAs are given as the first line therapy, despite the fact that most asthma is related to Th2, often eosinophilic, inflammation that requires an anti-inflammatory such as inhaled corticosteroids (ICS) to improve it. The patients rely on their SABA often to the exclusion of the ICS, perceiving it as the medication giving them benefit. This leads to the paradox regarding the issue of patient autonomy. As patients control their own disease, in their mind, using SABA as they feel necessary, they then follow up with the clinician who recognizes that SABA use is a marker of disease activity and inflammation, so then changes the therapy, adding an anti-inflammatory to reduce the inflammation. These medications, however, are to be taken as per the clinician instructions and therefore all patient autonomy is removed from the decision process. Patients have clearly demonstrated that they want control over their own disease, ${ }^{\mathrm{III}}$ so this is going to be an issue for many. There is also often a disconnect between the patients understanding of asthma control, often feeling that means relief of their symptoms when they have them compared with the clinicians view on asthma control which means preventing symptoms, disability and exacerbations.

The final paradox is one of safety concerns. The Salmeterol Multicentre Asthma Research Trial, ${ }^{\text {IV }}$ showed that long-acting beta agonist (LABA) monotherapy is potentially dangerous and was involved in the death of 19 young African American patients. This led to a black box warning for LABAs and even LABA/ICS (which has subsequently been removed after studies showed safety. ${ }^{\mathrm{V}}$ ) It is now well recognized that LABA monotherapy in Asthma (not so in COPD) is unsafe and should be avoided. Nobody, however, talks about the safety of SABA monotherapy. Does it confer the same risk as LABA monotherapy? I would suggest that it does based on the following information.

In the laboratory, SABAs will resolve the immediate bronchospasm of an allergic trigger, but it does not do anything for the delayed phase. Furthermore, regular use of SABAs have been shown to worsen

IPavord I, Beasley r, Agusti A, et al. After asthma: redefining airways diseases. Lancet. 2018;391( 10118):350-400.

IIO'Byrne PM, Jenkins C, Bateman ED, et al. The paradoxes of asthma management: time for a new approach?. Eur Respir J. 2017;50(3):1701103.

IIIPartridge MR, van der Molen T, Myrseth SE, et al. Attitudes and actions of asthma patients on regular maintenance therapy: the INSPIRE study.BMC Pulm Med. 2006;6:13.

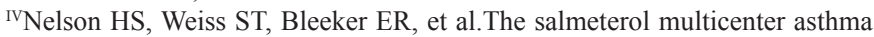
research trial: a comparison of usual pharmacotherapy for asthma or usual pharmacotherapy plus salmeterol. Chest. 2006;129(1):15-26.

visse W, Bateman E, Caplan A, et al. Combined Analysis of Asthma Safety Trials of Long-Acting 32-Agonists. N Engl J Med. 2018;378:2497-2505.
Volume 6 Issue 4 - 2019

\author{
Alan Kaplan \\ Family and Community Medicine, Canada
}

Correspondence: Alan Kaplan, Family Physician Airways Group of Canada, Tel +905883 I I00, Fax 905884 । I 95, Email For4kid@gmail.com

Received: November 28, 2019 | Published: December 09, 2019

the delayed phase response, ${ }^{\mathrm{VI}}$ which could explain why regular use of SABAs are actually pro-inflammatory. Recurrent SABA use is associated also with beta cell desensitization. ${ }^{\text {VII }}$ Older studies have shown clearly that while ICS raises the PD20 dose in bronchial hyperresponsiveness testing, the use of SABA actually lowers the dose. ${ }^{\text {VIII }}$ Regular SABA increases hyper-responsiveness in the lung, leading to greater sensitivity to triggers. ${ }^{\text {IX }}$

Clinically, we recognize from old Canadian data, ${ }^{\mathrm{X}}$ that increase SABA use related directly and proportionately to the risk of hospitalizations and death. UK data shows exacerbations occur more often in those using more than three SABA per year, ${ }^{\mathrm{XI}}$ with similar data in US studies. ${ }^{\mathrm{XII}}$ in the National Review of Asthma deaths, the consistent theme shown was that of SABA overuse and ICS underutilization for a variety of different reasons, but fatal outcomes. ${ }^{\text {XIII }}$

Patients become attached and use their SABAs for a variety of reasons that need to be appreciated by the clinician if we ever hope to change their behavior. They have good reasons to use them. They have a longstanding relationship with their SABA, it works for them, and may well be perceived as being less expensive than ICS containing therapies. Stigma of chronic illness may also prevent them for being on a regular controller treatment as denial is often an issue with any chronic disease. As such, it takes repeated education and counseling to explain the need of an anti-inflammatory therapy. Motivational counseling to understand the patient's reasons for their behaviors can go a long way to ensuring that adherence is obtained. ${ }^{\text {XIV }}$

${ }^{\mathrm{VI}}$ Gauvreau GM, Jordana M, Watson RM, et al. Effect of regular inhaled albuterol on allergen-induced late responses and sputum eosinophils in asthmatic subjects. Am J Respir Crit Care Med. 1997;156(9):1738-45.

${ }^{V I I}$ Lohse M, Benovic JL, Caron MG, et al. Multiple pathways of rapid beta 2-adrenergic receptor desensitization. Delineation with specific inhibitors. J Biol Chem. 1990;265(6):2302-3209.

${ }^{\mathrm{VIII} K e r r e b i j n ~ K F}$, et al. J Allergy Clin Immunol 1987; 79:653-9.

${ }^{\mathrm{Ix}}$ Beasley R, Bird G, Harper J, Weatherall M, et al. The further paradoxes of asthma management: time for a new approach across the spectrum of asthma severity. Eur Respir J. 2018;52(5).

${ }^{x}$ Spitzer W, Suissa S, Ernst P, et al. The use of beta-agonists and the risk of death and near death from asthma. N Engl J Med. 1992; 326(6):501-506.

${ }^{{ }^{x}}$ Hull S, McKibben S, Homer K, et al. Asthma prescribing, ethnicity and risk of hospital admission: an analysis of 35,864 linked primary and secondary care records in East London. NPJ Prim Care Respir Med. 2016;26:16049.

XIIStanford RH, Shah MB, D'Souza AO, et al. Short-acting $\beta$-agonist use and its ability to predict future asthma-related outcomes. Ann Allergy Asthma Immunol. 2012 Dec;109(6):403-407.

XIILevy M. The national review of asthma deaths: what did we learn and what needs to change?. Breathe (Sheff). 2015;11(1): 14-24.

${ }^{\mathrm{XIV}}$ Anstiss T. Motivational Interviewing in Primary Care. J Clin Psychol Med 
As such, the concept is to align our treatments with patient behaviors. We need to treat airway inflammation, but many of our patients just do not take the anti-inflammatory therapies. What we need is a different model of delivery of ICS in mild patients. Patients with moderate to severe asthma need to be on sufficient regular ICS containing therapy to obtain asthma control. That being said, it is clear from multiple studies in patients with moderate to severe disease, that changing the reliever from SABA to ICS/LABA, ${ }^{\mathrm{Xv}}$ decreases the risk of asthma exacerbations. Guidelines have clearly included the option for an ICS/LABA as a reliever for moderate to severe asthma. ${ }^{\mathrm{XVI}}$

What is new is how to deal with this issue in mild Asthma. Four trials have clearly shown that ICS/LABA prn is at least as good as regular low dose ICS, ${ }^{\mathrm{XVII}},{ }^{\mathrm{XVIII}}{ }_{\mathrm{XIX}}, \mathrm{XX}$ if not even better ${ }^{\mathrm{xx}}$ at preventing exacerbations, all at a fraction of the total dose of ICS. While there is no question that regular ICS outperforms ICS/LABA prn ${ }^{\mathrm{xvii}}$, these trials give us an option to use for those patients whose adherence is less reliable. It is what we are looking for, a novel inhaled steroid delivery mechanism. By treating the inflammation at the time it is happening, we can get vastly superior outcomes than not using steroid at all. Asthma is a variable disease and the level of inflammation does change, which does allow us to treat symptomatically. In a real world study xix, Fractionated Exhaled Nitric Oxide (FENO) a surrogate measurement of airway inflammation was reduced equally in both the regular ICS users compared with the ICS/LABA prn users compared to those using SABA alone. Interestingly, the concept of an antiinflammatory reliever in mild asthma was shown to be effective in a study in 2007 with an ICS/SABA (short acting bronchodilator) as well. ${ }^{\mathrm{XXI}}$

Exacerbations are important. They happen across the severity of asthma from mild to severe. They increase the risk of unscheduled visits, hospitalizations and mortality, as well as loss of long function each time. XXII They are managed with the use of systemic steroids, which are well known to have a myriad of serious side effects including abnormalities in glucose metabolism, fluid retention, weight gain, blood pressure elevation, peptic ulcer disease, avascular hip necrosis, adrenal suppression, skin thinning, muscle weakness,

Settings. 2009;16(1):87-93.

${ }^{\mathrm{xv}}$ Sobieraj DM, Weeda ER, Nguyen E, et al. Association of Inhaled Corticosteroids and Long-Acting $\beta$-Agonists as Controller and Quick Relief Therapy With Exacerbations and Symptom Control in Persistent Asthma: A Systematic Review and Meta-analysis. JAMA. 2018;319(14):1485-1496.

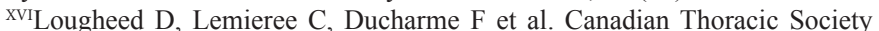
2012 guideline update: Diagnosis and management of asthma in preschoolers, children and adults. Can Respir J. 2012;19(6):e81-e88.

${ }^{\mathrm{XVII}} \mathrm{O}$ 'Byrne PM, FitzGerald JM, Bateman ED, et al. Inhaled Combined Budesonide-Formoterol as Needed in Mild Asthma. $\mathrm{N}$ Engl J Med. 2018;17;378(20):1865-1876.

XVIIIBateman ED, Reddel H, O'Byrne P, et al. As-Needed BudesonideFormoterol versus Maintenance Budesonide in Mild Asthma. N Engl J Med. 2018;378:1877-1887.

${ }^{\mathrm{xIx}}$ Beasley R, Holliday M, Reddel HK, et al. Controlled Trial of BudesonideFormoterol as Needed for Mild Asthma. N Engl J Med. 2019;380(21):2020 2030 .

${ }^{\mathrm{xx}}$ Hardy J, Baggott C1, Fingleton J, et al. Budesonide-formoterol reliever therapy versus maintenance budesonide plus terbutaline reliever therapy in adults with mild to moderate asthma (PRACTICAL): a 52-week, open-label, multicentre, superiority, randomised controlled trial. Lancet. 2019;394:919928.

xxIPapi A, Canonica GW, Maestrelli P, et al. Rescue use of beclomethasone and albuterol in a single inhaler for mild asthma. N Engl J Med. 2007;356(20):2040 2052

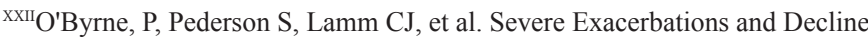
in Lung Function in Asthma. Am J Respir Crit Care Med. 2009; 179(1):19-24.

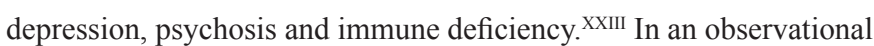
study on outcomes post even short course ICS exposure, the risk in the month following treatment of sepsis was increased 5.3 fold, venous thromboembolism 3.33 fold and fracture 1.87 fold. ${ }^{\text {xxIV }}$

The Global Initiative for Asthma Care (GINA) recommendations done this year (2019), ${ }^{\mathrm{XXV}}$ have adopted this principle, recommending that the appropriate reliever across all severities of asthma would be an ICS/LABA. Certainly, depending on the controller used, SABA may be continued, especially when using a different LABA as safety of combination of LABAs has not been established. However, they were very clear that SABA monotherapy is NOT recommended. In Step one (symptoms twice a month) or Step 2 (twice a week), the recommendations for therapy initation are either regular ICS or ICS/ LABA prn. GINA made these recommendations for two important reasons. First to help decrease exacerbations and second, to attempt to keep our message of treating airway inflammation consistent and central to asthma management.

Change is hard. We need to start from the beginning by not initiating therapy with SABA monotherapy and therefore not establish that relationship in the first place. Perhaps, it is time to remove most SABA therapy from routine asthma management,xxvi (there will always be exceptions which can include potentially neutrophilic asthma and exercise induced bronchospasm (EIB) which may not have Th2 inflammation as the central issue). Using an anti-inflammatory reliever ICS/Formoterol allows this to happen. As the Sygma trials did not go below the age of 12 , there is no evidence currently to support the use of ICS/formoterol as a reliever at these ages. However, the GINA recommendations recognized this and in their statement on children below the age of 12 , they were consistent in their message of an anti-inflammatory reliever by suggesting that whenever a SABA is used, a dose of ICS should be given to accompany it.

Patients may want to hold on to their SABAS, but it is up to us to ensure that they do not manage a disease in which airway inflammation is the central theme with a treatment that does not deal with this inflammation.

\section{Funding}

None.

\section{Acknowledgments}

None.

\section{Conflicts of interest}

Dr. Kaplan has the following conflicts as either a member of an advisory board or speakers bureau for the following companies: Astra Zeneca, Behring, Boehringer Ingelheim, Covis, Griffols, GSK Merck Frosst, Novartis, Novo Nordisk, Pfizer, Purdue, Sanofi, Teva, Trudel. xxvi

\footnotetext{
xxIILLefebvre P, Duh MS, Lafeuille MH, et al. Acute and chronic systemic corticosteroid-related complications in patients with severe asthma. J Allergy Clin Immunol. 2015;136(6):1488-1495.

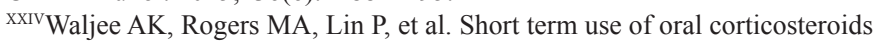
and related harms among adults in the United States: population based cohort study. BMJ. 2017;357:j1415.

${ }^{\mathrm{xxv}}$ Global Initiative for Asthma. Global Strategy for Asthma Management and Prevention, 2019. 2019.

${ }^{x x v i}$ Martin, M, Harrison T. Is it time to move away from short-acting beta-
} agonists in asthma management? ERSournal 2019;53(4):1802223. 